\title{
Uma avaliação empírica do tamanho ótimo dos municípios
}

\author{
Tito Belchior Silva Moreira* \\ Anna Rita Scott Kilson ${ }^{\star *}$ \\ Celso Vila Nova de Souza***
}

\begin{abstract}
Esta pesquisa tem o objetivo de realizar uma investigação empírica sobre o tamanho ótimo dos municípios, isto é, a quantidade de habitantes que propicia o menor nível de despesas em relação ao PIB municipal, de modo que se obtenha escala econômica para otimização da aplicação dos recursos públicos. Este estudo analisa uma amostra de dados de 4.835 municípios com população inferior a 50.000 habitantes, que representam $89 \%$ do total de municípios brasileiros. A base de dados reúne informações de receitas e despesas municipais, extraídas do Finanças do Brasil - Dados Contábeis dos Municípios - Finbra 2010 e dados socioeconômicos do Censo Demográfico do IBGE 2010 e do PIB dos municípios do IBGE 2010. Os resultados empíricos indicam que o tamanho ótimo de população para um município brasileiro equivale aproximadamente a 31.667 habitantes por cidade, com base em métodos econométricos como mínimos quadrados ordinários com desvio padrão robusto. Esse porte populacional proporciona ganhos de escala na administração pública e confere maior autonomia local em relação ao governo central para ofertar bens públicos de qualidade.
\end{abstract}

Palavras-chave: Federalismo fiscal. Tamanho ótimo dos municípios. Despesas públicas.

\footnotetext{
* Universidade Católica de Brasília (UCB), campus Taguatinga, Brasília-DF, Brasil (titoeco@yahoo.com.br; http://orcid. org/0000-0002-2382-1480).

** Caixa Econômica Federal, Brasília-DF, Brasil (annakilson@hotmail.com; http://orcid.org/0000-0003-2981-1846).

*** Universidade de Brasília (UnB), Brasília-DF, Brasil (celso.vilanova@gmail.com; https://orcid.org/0000-0003-3623-9251).
} 


\section{Introdução}

0 presente trabalho se propõe a contribuir para o debate sobre o tamanho ideal da população de municípios de modo que se alcance o menor nível de despesas em relação ao PIB, buscando o aperfeiçoamento da aplicação de recursos públicos e, consequentemente, a melhoria da qualidade de vida nos municípios brasileiros. Esta pesquisa analisa uma amostra de dados de 4.835 municípios brasileiros com população inferior a 50.000 habitantes, composta pelas bases de receitas e despesas municipais, extraídas do Finanças do Brasil - Dados Contábeis dos Municípios - Finbra 2010, de dados socioeconômicos do Censo Demográfico do IBGE 2010 e de PIB dos municípios do IBGE 2010. Nesse contexto, o artigo contribui para o tema em discussão, para o caso da economia brasileira, ao utilizarmos métodos empíricos que mostram uma relação não linear entre as despesas dos municípios e suas respectivas populações de forma a calcularmos o tamanho ótimo dos municípios.

O movimento histórico de descentralização política e fiscal, que ocorre no mundo há décadas, tem sido motivado pela busca de eficiência na oferta de bens públicos. De acordo com Tiebout (1956), a prestação de serviços pelos entes infranacionais pode facilitar o conhecimento das preferências das comunidades e das especificidades do local, aumentando as possibilidades de fornecimento de serviços focados nas demandas. Entretanto, as características distintas das localidades e as divergências de interesses entre os governos nacionais e locais representam grandes desafios para a otimização da gestão pública.

A descentralização territorial, ainda que tenha sido uma medida básica adotada quase universalmente, principalmente, para fortalecimento da democracia local, apresenta limitações do ponto de vista do desempenho econômico dos governos locais. Essa constatação tem estimulado o debate sobre a busca por economias de escala nos pequenos municípios desmembrados (SOUKOPOVÁ et al., 2014).

Segundo Gasparini e Miranda (2011), a descentralização fiscal é reconhecida por diversos autores como um caminho para a melhoria da gestão pública. Um ambiente descentralizado promove a competição entre os governos locais para oferecerem os melhores níveis de bens públicos, com um menor volume de impostos. Entretanto, a descentralização pode aumentar as desigualdades regionais. A autonomia fiscal tende a privilegiar os governos que possuem mais recursos e melhor capacidade técnica. Esse efeito negativo, associado às disparidades de receitas entre os governos locais, pode ser reduzido por meio de transferências de recursos do governo nacional.

Os mecanismos de equalização fiscal têm sido utilizados em várias nações com a finalidade de compensar diferenças de riqueza, por meio de políticas de subvenções do governo nacional para os entes infranacionais, visando a promoção do desenvolvimento nacional e a potencialização da aplicação dos recursos públicos (GRUBER, 2016).

A descentralização fiscal no Brasil teve início durante o sistema político centralizado vigente nos governos militares, com a criação do Fundo de Participação dos Municípios 
(FPM), instituído pela Emenda Constitucional n. 18 da Constituição de 1946, de 1ํ de dezembro de 1965, e regulamentado pelo Código Tributário Nacional em 1966 (GOMES; MAC DOWELL, 2000).

O FPM é um instrumento de transferência de recursos da União para os entes municipais, criado, segundo Mendes (2004), com o objetivo de reduzir desequilíbrios entre os entes, devendo priorizar a aplicação de seus recursos em municípios com baixa capacidade de arrecadação ou com alta pressão por gastos. Os recursos do FPM são provenientes de $24,5 \%$ da arrecadação do Imposto de Renda (IR) e do Imposto sobre Produtos Industrializados (IPI). Os critérios de partilha categorizam os municípios em três classes: as capitais estaduais e Brasília; os do interior (municípios que não são capitais); e os da reserva (municípios do interior com população superior a 142.633 habitantes).

A existência de transferências traz novos desafios, afirmam Gasparini e Miranda (2011). Qualquer tipo de repasse de recursos entre instâncias governamentais gera incentivos que devem ser considerados no desenho federativo. As subvenções intergovernamentais podem trazer benefícios em termos do equilíbrio e do alcance de objetivos nacionais, mas também podem criar distorções, como o "problema do carona” (free-rider), que ocorre quando os serviços públicos oferecidos à população de determinado município são custeados pelos impostos pagos pela população de outro que não usufrui do que paga.

Luduvice e De Biase (2020) argumentam que a Constituição de 1988 conferiu aos estados a atribuição de legislar sobre a criação de municípios. Nesse contexto, muitos estados flexibilizaram a exigência de quantitativo populacional mínimo, o que facilitou a criação de mais de 1.300 novos municípios em menos de dez anos. 0 considerável aumento na quantidade de pequenos municípios, no início da década de 1990, provocou a reação de lideranças políticas, que se mobilizaram para conter outras expansões. Assim, com a edição da Emenda Constitucional n. 15, de 1996, foi restabelecida a competência federal de legislar sobre a matéria.

No sentido contrário ao dos desmembramentos de municípios ocorridos no Brasil na década de 1990, no mesmo período, outros países como Holanda e Canadá fundiram municípios com o objetivo de racionalizar as despesas na prestação de serviços públicos, aumentando a economia de escala (SOUKUPOVA et al., 2014). Movimentos semelhantes ocorreram na Nova Zelândia (KORTT; DOLLERY; DREW, 2015), Inglaterra (ANDREWS, 2015) e Finlândia (MOISIO; UUSITALO, 2013).

O impacto causado pelas divisões de municípios, de acordo com Swianiewicz e Lukomska (2017), vem sendo estudado em diversos países que passaram por processo de fragmentação territorial. A maior parte do conhecimento empírico sobre as economias de escala em governos locais foi desenvolvida nos Estados Unidos, na Austrália e em países europeus com tradição de descentralização. Ainda que haja divergências no que se refere aos ganhos de escala decorrentes de reformas territoriais, conforme apontam Gendzwill, Kurniewick e Swianiewicz (2020), há estudos que mostram que fusões de municípios reduzem o gasto público (BLESSE; BASKARAN, 2013). 
Este trabalho é dividido em quatro seções, além dessa breve introdução. A seguir, abordam-se o referencial teórico e a revisão de literatura sobre o tema e, posteriormente, são descritas a metodologia adotada para a realização da análise empírica, as bases de dados, com suas respectivas fontes, e as variáveis selecionadas. São discutidos os resultados empíricos do ensaio, ilustrados com quadros e gráficos, e, por fim, apresentam-se as conclusões do estudo.

\section{Referencial teórico e revisão da literatura}

A literatura sobre finanças públicas apresenta contribuições de diversos autores ao longo de séculos. Desde 1739, David Hume já havia observado a existência de atividades que não geravam lucro, se executadas individualmente, mas que traziam benefícios para toda a sociedade e, desse modo, só poderiam ser viabilizadas por meio de ação coletiva. Mais tarde, em 1954 e 1955, Paul Samuelson, em dois artigos curtos, desenvolveu as bases matemáticas para a conceituação de bens públicos e a fundamentação da teoria econômica da descentralização (SANDMO, 1989).

De acordo com a formulação de Samuelson (1954), bem público é aquele que está disponível para qualquer indivíduo, cujo consumo por uma pessoa não exclui o consumo por outra. Assim, o indivíduo não teria incentivo para revelar sua necessidade real do bem, deixando que outros revelassem suas necessidades e pagassem proporcionalmente por elas, enquanto quem não revelou poderia desfrutar do bem sem o respectivo pagamento.

A precificação de Lindahl (1958) é uma teoria sobre a oferta eficiente de bens públicos baseada no princípio de que os indivíduos revelam honestamente sua demanda, ou seja, o montante que estão dispostos a pagar e o governo cobra deles esse valor informado. Nesse sentido, há três problemas que devem ser pontuados: a revelação das preferências pode não corresponder à realidade, uma vez que os indivíduos podem mentir sobre sua disposição de pagamento; o conhecimento das preferências pode ser impreciso, na medida em que os indivíduos podem não saber avaliar o bem; e, por fim, na agregação de preferências, mesmo com os indivíduos indicando a demanda real com a devida avaliação, existe a dificuldade de agregar valores individuais em um valor social (GRUBER, 2009).

Musgrave (1939) dá continuidade ao debate a respeito da oferta de bens públicos, discutindo a tributação de acordo com o princípio do benefício, em que cada contribuinte seria tributado de acordo com sua demanda por bens públicos. 0 autor aponta como fragilidade da teoria a dificuldade de revelação da demanda real pelos bens públicos. Se, por um lado, os indivíduos têm dificuldade de avaliar um bem público, por outro, eles ainda costumam tentar minimizar suas próprias contribuições. Além disso, grupos políticos têm o hábito de se empenhar para forçar uma contribuição máxima.

De acordo com Mendes (2004), os países podem organizar suas estruturas político-constitucionais de três formas: unitárias, federais e confederadas. As estruturas governamentais unitárias concentram as decisões no governo nacional, não existindo outros níveis 
de governo. Nas localidades há apenas agências locais vinculadas ao governo nacional. No sistema federativo os poderes são divididos entre diferentes níveis de governo, com preponderância do nível nacional que garante a soberania do país, atribuindo distintos graus de autonomia aos níveis locais. A organização federativa facilita a diversidade cultural em um mesmo país. Os sistemas confederados são compostos por estados mais fortes que o governo central. Nesses casos, o governo central tem um papel articulador de esforços para obter vantagens advindas da integração sem perder a soberania política.

Gruber (2009) descreve o federalismo fiscal como a distribuição de responsabilidades entre os níveis de governo, ou seja, quais atividades devem ser executadas por cada nível de governo. 0 federalismo fiscal ótimo suscita a discussão sobre administração mais ou menos descentralizada e se as desigualdades entre as localidades devem ser equalizadas por meio de subvenções dos governos nacionais.

A partir dos trabalhos desenvolvidos por Richard Musgrave (1939) e Paul Samuelson (1954), Charles Tiebout (1956) compara o mercado privado com o público e identifica que a busca e a competição, que garantem a oferta ótima de bens privados, eram fatores ausentes na oferta centralizada de bens públicos. Nesse caso, a população escolheria residir em um local que melhor atendesse à sua demanda por bens públicos e, se isso não ocorresse, poderia se mudar para outra localidade vizinha - "votando com os pés" -, manifestando, assim, suas preferências. Por meio dessa premissa, Tiebout defendeu que a oferta local aumenta a eficiência no fornecimento de bens públicos, favorecendo a revelação de preferências e a agregação da demanda.

A teoria desenvolvida por Tiebout (1956) baseia-se na ideia de que a competição entre localidades pressiona a oferta de bens públicos. 0 modelo formulado supõe a existência de populações que se dividem em localidades que fornecem distintos níveis de bens públicos, sendo que em cada local os residentes possuem exatamente o mesmo gosto por bens públicos, eliminando, assim, o problema de agregação de preferências. Além disso, a receita para o financiamento de bens públicos vem da cobrança de imposto uniforme, arrecadado de todos os indivíduos. Desse modo, não há problema de revelação de preferências, porque não existe incentivo para que os indivíduos mintam e subestimem suas preferências, uma vez que o imposto é o mesmo para qualquer pessoa.

Apesar da relevância teórica do modelo, existem diversos problemas que dificultam a predição de que a oferta de bens públicos será eficiente. Conforme Gruber (2009), a primeira condição difícil de ser aplicada é a da mobilidade perfeita: não basta o indivíduo querer "votar com os pés", isso precisa ser viável, mas na prática tal ação é improvável. 0 modelo exige uma quantidade de localidades que permitam que a população escolha onde residir de acordo com suas preferências por bens públicos e, ao mesmo tempo, as localidades precisam ter populações suficientemente grandes para garantir economias de escala para custear os bens públicos.

Gruber (2009) argumenta que no modelo de Tiebout, ainda que não represente uma descrição exata da realidade, as variações de tributação e de gastos locais efetivamente 
alteram a mobilidade e os preços de residências. Isso confirma as predições do modelo em relação aos comportamentos. Dessas constatações depreende-se que a teoria de Tiebout traz implicações normativas para a otimização do federalismo fiscal na medida em que relaciona o volume de oferta de bens públicos a três fatores. 0 primeiro deles é representado pela existência de vínculos entre impostos e benefícios. Os residentes nas localidades entendem que seus impostos estão relacionados com os bens públicos que recebem. 0 segundo fator determinante do nível ótimo de descentralização é a geração de transbordamentos positivos sobre outras localidades, isto é, a oferta de bens públicos por qualquer localidade será insuficiente. Nessa situação, os bens públicos devem ser ofertados por níveis mais altos de governo. 0 terceiro fator é a economia de escala na oferta de alguns tipos de bens públicos específicos que não são ofertados eficientemente pelos governos locais.

Na visão de Wallace Oates (1972), o federalismo fiscal é um meio termo entre a administração pública centralizada e a predominantemente descentralizada. Segundo o autor, o federalismo fiscal pode juntar as vantagens de ambos os modelos de gestão e, ao mesmo tempo, reduzir os aspectos negativos desses tipos de administração. Isto é, um governo completamente descentralizado teria dificuldades para executar políticas macroeconômicas e de distribuição de renda, assim como outras ações de abrangência nacional (MENDES, 2004). Por outro lado, um governo completamente centralizado teria dificuldade para conhecer as preferências locais e ofertar bens públicos adequados.

No Brasil, a descentralização política ocorrida a partir da Constituição Federal de 1988 promoveu significativas mudanças no federalismo brasileiro. Guedes e Gasparini (2007) afirmam que houve reconhecimento dos municípios como entes da federação em condições equivalentes aos estados, em relação a diretos e deveres, passando a assumir maior importância na oferta de serviços públicos. Nesse contexto, o fortalecimento financeiro dos municípios brasileiros, em geral, está mais relacionado ao aumento dos recursos transferidos da União, por meio do Fundo de Participação dos Municípios - FPM, do que à ampliação de suas capacidades tributárias. A descentralização política provocou a proliferação de pequenos municípios criados a partir de distritos emancipados. De acordo com Gomes e Mac Dowell (2000), esse fenômeno ocorreu porque as populações e as elites políticas municipais perceberam que isso lhes traria mais status e ampliaria os recursos para a localidade.

Os benefícios financeiros proporcionados aos novos municípios motivaram a grande quantidade de emancipações após a Constituição de 1988. Segundo Bremaeker (2010), os novos municípios, geralmente, não possuem passivos acumulados por gestões anteriores e possuem folhas de pagamento com menos aposentados e pensionistas, além de serem favorecidos pelos critérios de repartição do FPM. Pelos critérios de repartição vigentes, quando municípios com população inferior a 10 mil habitantes se dividem em dois, ambos passam a receber a cota mínima do FPM, o que provoca um acréscimo considerável no valor do repasse. De um modo geral, os municípios que passam por processos emancipatórios 
aumentam o valor do FPM per capita. Esse benefício financeiro concedido aos novos municípios é rateado pelos outros municípios do estado, que sofrem uma redução na parcela de repasse federal.

Souza e Ramos (1999) afirmam que os municípios brasileiros com população inferior a 25.000 habitantes são mais ineficientes para ofertar serviços públicos. Partindo dessa constatação, Luduvice e De Biase (2020) deduzem que a onda de emancipações municipais, ocorrida nos anos 1990, pode ter aumentado o custo médio da oferta de serviços públicos, considerando que $78 \%$ dos municípios resultantes dos desmembramentos tinham menos de 25.000 habitantes, em 2015.

0 trabalho desenvolvido por Dahis e Szerman (2020) constatou que os municípios brasileiros que passaram por processo de subdivisão e receberam transferências de recursos do governo federal melhoraram seus índices de desenvolvimento local. Observou-se a ampliação da atividade econômica, da prestação de serviços públicos e da infraestrutura urbana, bem como o aumento da oferta de empregos. A pesquisa não identificou efeitos negativos para os municípios que perderam território. A conclusão apresentada no artigo demonstra que o desmembramento de municípios pode ser uma alternativa para estimular o desenvolvimento regional de localidades pequenas e isoladas, conjugado com o apoio financeiro do governo central, por meio de transferências de fundos de recursos.

A análise de Bartolini (2015) realizada em uma amostra de países da Organização para a Cooperação e o Desenvolvimento Econômico - OCDE apresenta evidências empíricas de que a fragmentação municipal gera impactos diferenciados em áreas urbanas e rurais. $A$ fragmentação dos municípios afeta negativamente no crescimento do PIB per capita quanto mais urbana for a região. Nas áreas com população rural superior a $30 \%$ da população total, a fragmentação demonstra uma correlação positiva com o crescimento da economia. A redução da fragmentação municipal pode melhorar o desempenho econômico de territórios onde a maioria da população vive em áreas urbanas, sobretudo nas regiões metropolitanas.

Holzer et al. (2009), analisando a relação entre o tamanho ótimo do município e sua eficiência, sugerem que o custo per capita de serviços públicos apresenta um padrão similar à curva de custo médio das firmas, isto é, uma parábola com formato de $U$ em função do tamanho da população do município. Observa-se que o custo diminui à medida que a população aumenta até atingir um ponto mínimo em torno de 25.000 habitantes, ficando estável até cerca de 250.000 habitantes e, a partir daí, volta a crescer. A curva que ilustra a relação entre o tamanho do município e a eficiência mostra que os municípios com populações menores têm um custo per capita mais alto.

Por outro lado, a revisão da literatura realizada por Byrnes e Dollery (2002) não constatou uma relação estatisticamente significante entre o custo per capita de oferta de serviços públicos e o tamanho da população do município. Segundo eles, as evidências de que existem retornos crescentes de escala na provisão de serviços públicos municipais não são facilmente confirmadas e, em alguns casos, são contraditórias. De acordo com Drew 
et al. (2014), vem se consolidado a visão de que as características dos retornos dependem dos serviços ofertados e variam conforme a utilização intensiva de capital ou de trabalho.

Dollery e Fleming (2006) defendem que a economia de escala tem ampla aplicação no contexto dos governos locais. 0 principal argumento é que se cada município produz serviços semelhantes, com economia de escala substancial, logo, um sistema fragmentado em pequenos municípios resulta em despesas mais altas para o mesmo nível de serviço, comparando-se com um sistema com menos municípios de maior porte. De acordo com Houlberg (2010), os gastos per capita para manutenção de uma estrutura de gestão, bem como de um conselho municipal, podem diminuir à medida que aumenta a quantidade de habitantes no local. Cada município precisa ter uma quantidade mínima de pessoal, equipamentos e instalações para ofertar os serviços públicos demandados pela população.

Matejova et al. (2017) investigaram a relação entre o tamanho de um município e economias de escala na prestação de serviços municipais, tais como atividades esportivas e de lazer, cultura, proteção ambiental, habitação, educação, dentre outros, para uma amostra de 205 municípios da República Tcheca. 0 estudo, que utiliza como variável dependente as despesas municipais per capita, identificou a existência de economia de escala nas despesas com educação.

A pesquisa elaborada por Swianiewicz e Lukomska (2017) analisa os desmembramentos de municípios ocorridos na Polônia, verificando se os resultados das emancipações equivalem a um espelho das consequências das fusões, isto é, se apresentam simetria, nesse caso, se fortalecem a hipótese de que o tamanho do município realmente importa. Os resultados apontam, claramente, a existência de uma economia de escala em relação aos gastos administrativos, entretanto, no que se refere aos gastos gerais municipais, a economia de escala torna-se menos visível. As mesmas constatações foram obtidas em estudos sobre as fusões de municípios na Dinamarca, Suécia, Alemanha e Países Baixos. Ainda que possam existir ganhos na subdivisão de municípios, seja para o fortalecimento da democracia ou para a redução de conflitos locais, os efeitos negativos identificados na fragmentação do território, principalmente para os governos de municípios de pequeno porte, devem ser apresentados aos formuladores de políticas em níveis nacional e local e também às comunidades locais que discutem o número e o tamanho de suas jurisdições territoriais.

Os estudos que consideram como variáveis dependentes as despesas per capita, desenvolvidos por Luduvice e De Biase (2020) para municípios brasileiros, por Swianiewicz e Lukomska (2017) para municípios poloneses e por Matejova et al. (2017) para municípios da República Tcheca, constataram a existência de economia de escala, pelo menos, para uma categoria de gastos municipais. Todavia, na pesquisa de Holcombe e Williams (2009), que analisou uma amostra de municípios americanos, o coeficiente da variável população apresentou-se estatisticamente insignificante quando a variável densidade demográfica foi inserida no modelo. Drew et al. (2014) chegaram a um resultado equivalente para análise de municípios da Austrália. 
Uma discussão mais focada no tratamento do modelo federativo brasileiro pós-Constituição de 1988, em que pese a descentralização das políticas sociais e seus efeitos sobre a gestão pública dos pequenos e médios municípios, é abordada por um trabalho recente de Lima e Leite (2021), no qual é avaliado o efeito da emancipação de munícipios sobre as finanças públicas locais. Os autores destacam que o Brasil experimentou uma onda de criação de munícipios nos anos 1990, com a emancipação de 1.016 administrações locais. Eles avaliam as consequências das emancipações sobre diferentes características fiscais. Partindo-se de uma abordagem quase experimental baseada no método de diferenças-em-diferenças, os autores comparam os munícipios emancipados com os que tentaram se emancipar e não conseguiram. Os resultados empíricos mostram um incremento dos gastos associados à manutenção da estrutura de governo e aos bens de capital. Por outro lado, observa-se que os gastos sociais não sofreram um impacto significativo. No que tange à arrecadação local, não foram encontradas mudanças na receita própria. Entretanto, houve aumento de recursos oriundos de transferências intergovernamentais e de operações de crédito. Esses resultados sugerem que o choque de descentralização mudou a composição do gasto local e trouxe uma maior dependência fiscal para os governos locais. Por fim, vale destacar que este artigo cita diversos autores que trabalham nessa mesma linha e que aprofundam a discussão sobre esse tema. Destaque-se ainda que o IBGE possui bases de dados para esses modelos empíricos, como a Pesquisa de Informações Básicas Municipais do IBGE.

Adicionalmente, vale ressaltar políticas públicas realizadas com o objetivo de mitigar a pobreza. Nesse sentido, Santos, Miranda e Moreira (2012) avaliam a pobreza frente às políticas públicas adotadas pelo governo brasileiro, destacando quatro vertentes centrais: a educação superior, a renda per capita, o desemprego e o Programa Bolsa Família. Nos últimos anos, o governo brasileiro tem mostrado instrumentos para combater a pobreza por meio de políticas de transferência de renda aos mais pobres. Os autores mostram que, apesar das fragilidades evidenciadas pelo Bolsa Família, os resultados sinalizam que essa política tem apresentado um efeito positivo sobre os índices de pobreza no Brasil. Além disso, as estratégias que buscam interromper a reprodução do pauperismo na história do desenvolvimento social brasileiro, tais como o crescimento do PIB, a ampliação do acesso ao ensino superior, a diminuição do desemprego e as políticas de transferência de renda, não podem ser tomadas como contraditórias e excludentes, mas sim como complementares e essenciais, em função da gravidade do problema, que há décadas assola nossa sociedade.

\section{Metodologia}

Destaque-se que o Censo de 2010 apresenta 5.565 municípios em todo o país. Nesse contexto, a pesquisa analisa um conjunto de dados de municípios brasileiros, composta pelas bases contábeis de receitas e despesas municipais, extraídas do Finanças do Brasil - Dados Contábeis dos Municípios - Finbra 2010, da Secretaria do Tesouro Nacional - STN, 
de dados socioeconômicos do Censo Demográfico 2010 do IBGE e de PIB dos municípios do IBGE 2010. Ao serem descartados os municípios que não possuíam dados satisfatórios, restou uma amostra de 4.835 municípios brasileiros que representam a base de dados a ser utilizada.

As variáveis escolhidas mostram vários indicadores socioeconômicos dos municípios que podem contribuir para explicar o comportamento das finanças públicas no que tange às despesas orçamentárias como proporção do PIB. Dessa forma, foram selecionadas as bases de dados sobre os quantitativos populacionais, receitas e despesas orçamentárias, PIB Municipal, educação, renda domiciliar per capita e condições dos domicílios, dentre outros, conforme a descrição no Quadro 1.

QUADRO 1

Relação de variáveis componentes do estudo com suas respectivas fontes

\begin{tabular}{|c|c|c|c|}
\hline \multicolumn{2}{|r|}{ Variáveis } & Descrição das bases & Fontes \\
\hline \multirow{6}{*}{ População } & População & $\begin{array}{l}\text { Tabela } 3175 \text { - População residente, por cor ou raça, } \\
\text { segundo a situação do domicílio, o sexo e a idade }\end{array}$ & $\begin{array}{l}\text { Censo } \\
\text { Demográfico } \\
\text { IBGE } 2010\end{array}$ \\
\hline & Urbana & $\begin{array}{l}\text { Tabela } 3175 \text { - População residente, por cor ou raça, } \\
\text { segundo a situação do domicílio, o sexo e a idade }\end{array}$ & $\begin{array}{l}\text { Censo } \\
\text { Demográfico } \\
\text { IBGE } 2010\end{array}$ \\
\hline & Rural & $\begin{array}{l}\text { Tabela } 3175 \text { - População residente, por cor ou raça, } \\
\text { segundo a situação do domicílio, o sexo e a idade }\end{array}$ & $\begin{array}{l}\text { Censo } \\
\text { Demográfico } \\
\text { IBGE } 2010\end{array}$ \\
\hline & $\begin{array}{l}\text { Densidade } \\
\text { demográfica }\end{array}$ & $\begin{array}{l}\text { Tabela } 3175 \text { - População residente, por cor ou raça, } \\
\text { segundo a situação do domicílio, o sexo e a idade }\end{array}$ & $\begin{array}{l}\text { Censo } \\
\text { Demográfico } \\
\text { IBGE } 2010\end{array}$ \\
\hline & Faixas etárias & $\begin{array}{l}\text { Tabela } 3175 \text { - População residente, por cor ou raça, } \\
\text { segundo a situação do domicílio, o sexo e a idade }\end{array}$ & $\begin{array}{l}\text { Censo } \\
\text { Demográfico } \\
\text { IBGE } 2010\end{array}$ \\
\hline & $\begin{array}{l}\text { Classes de tamanho } \\
\text { da população } \\
\text { (variável dummy) }\end{array}$ & $\begin{array}{l}\text { Tabela } 1290 \text { - Número de municípios e população } \\
\text { nos Censos Demográficos por tamanho da população } \\
\text { (dummies até } 2.000 \text {; de } 2.001 \text { a } 5.000 ; \text { de } 5.001 \text { a } \\
\text { 10.000; de } 10.001 \text { a } 20.000 \text {; de } 20.001 \text { a } 50.000 ; \text { de } \\
50.001 \text { a } 100.000 \text {; de } 100.001 \text { a } 500.000 \text { e mais de } \\
500.000 \text { ) }\end{array}$ & $\begin{array}{l}\text { Censo } \\
\text { Demográfico } \\
\text { IBGE } 2010\end{array}$ \\
\hline \multirow{6}{*}{$\begin{array}{l}\text { Educação } \\
\text { (pessoas) }\end{array}$} & $\begin{array}{l}\text { Taxa de } \\
\text { alfabetização(\%) }\end{array}$ & $\begin{array}{l}\text { Tabela } 1383 \text { - Taxa de alfabetização das pessoas de } \\
10 \text { anos ou mais de idade por sexo }\end{array}$ & $\begin{array}{l}\text { Censo } \\
\text { Demográfico } \\
\text { IBGE } 2010\end{array}$ \\
\hline & $\begin{array}{l}\text { Sem instrução } \\
\text { e fundamental } \\
\text { incompleto }\end{array}$ & $\begin{array}{l}\text { Tabela } 3540 \text { - Pessoas de } 10 \text { anos ou mais de } \\
\text { idade, por nível de instrução, segundo a situação do } \\
\text { domicílio, o sexo, a cor ou raça e os grupos de idade }\end{array}$ & $\begin{array}{l}\text { Censo } \\
\text { Demográfico } \\
\text { IBGE } 2010\end{array}$ \\
\hline & $\begin{array}{l}\text { Fundamental } \\
\text { completo e médio } \\
\text { incompleto }\end{array}$ & $\begin{array}{l}\text { Tabela } 3540 \text { - Pessoas de } 10 \text { anos ou mais de } \\
\text { idade, por nível de instrução, segundo a situação do } \\
\text { domicílio, o sexo, a cor ou raça e os grupos de idade }\end{array}$ & $\begin{array}{l}\text { Censo } \\
\text { Demográfico } \\
\text { IBGE } 2010\end{array}$ \\
\hline & $\begin{array}{l}\text { Médio completo e } \\
\text { superior incompleto }\end{array}$ & $\begin{array}{l}\text { Tabela } 3540 \text { - Pessoas de } 10 \text { anos ou mais de } \\
\text { idade, por nível de instrução, segundo a situação do } \\
\text { domicílio, o sexo, a cor ou raça e os grupos de idade }\end{array}$ & $\begin{array}{l}\text { Censo } \\
\text { Demográfico } \\
\text { IBGE } 2010\end{array}$ \\
\hline & Superior completo & $\begin{array}{l}\text { Tabela } 3540 \text { - Pessoas de } 10 \text { anos ou mais de } \\
\text { idade, por nível de instrução, segundo a situação do } \\
\text { domicílio, o sexo, a cor ou raça e os grupos de idade }\end{array}$ & $\begin{array}{l}\text { Censo } \\
\text { Demográfico } \\
\text { IBGE } 2010\end{array}$ \\
\hline & Não determinada & $\begin{array}{l}\text { Tabela } 3540 \text { - Pessoas de } 10 \text { anos ou mais de } \\
\text { idade, por nível de instrução, segundo a situação do } \\
\text { domicílio, o sexo, a cor ou raça e os grupos de idade }\end{array}$ & $\begin{array}{l}\text { Censo } \\
\text { Demográfico } \\
\text { IBGE } 2010\end{array}$ \\
\hline
\end{tabular}


(continuação)

\begin{tabular}{|c|c|c|c|}
\hline \multicolumn{2}{|r|}{ Variáveis } & Descrição das bases & Fontes \\
\hline \multirow{8}{*}{$\begin{array}{l}\text { Classes de } \\
\text { rendimento } \\
\text { nominal } \\
\text { mensal } \\
\text { domiciliar } \\
\text { per capita } \\
\text { (unidades) }\end{array}$} & $\begin{array}{l}\text { Até } 1 / 4 \text { de salário } \\
\text { mínimo }\end{array}$ & $\begin{array}{l}\text { Tabela } 3261 \text { - Domicílios particulares permanentes, } \\
\text { por classes de rendimento nominal mensal domiciliar } \\
\text { per capita }\end{array}$ & $\begin{array}{l}\text { Censo } \\
\text { Demográfico } \\
\text { IBGE } 2010\end{array}$ \\
\hline & $\begin{array}{l}\text { Mais de } 1 / 4 \text { a } 1 / 2 \\
\text { salário mínimo }\end{array}$ & $\begin{array}{l}\text { Tabela } 3261 \text { - Domicílios particulares permanentes, } \\
\text { por classes de rendimento nominal mensal domiciliar } \\
\text { per capita }\end{array}$ & $\begin{array}{l}\text { Censo } \\
\text { Demográfico } \\
\text { IBGE } 2010 \\
\end{array}$ \\
\hline & $\begin{array}{l}\text { Mais de } 1 / 2 \text { a } 1 \\
\text { salário mínimo }\end{array}$ & $\begin{array}{l}\text { Tabela } 3261 \text { - Domicílios particulares permanentes, } \\
\text { por classes de rendimento nominal mensal domiciliar } \\
\text { per capita }\end{array}$ & $\begin{array}{l}\text { Censo } \\
\text { Demográfico } \\
\text { IBGE } 2010 \\
\end{array}$ \\
\hline & $\begin{array}{l}\text { Mais de } 1 \text { a } 2 \text { salários } \\
\text { mínimos }\end{array}$ & $\begin{array}{l}\text { Tabela } 3261 \text { - Domicílios particulares permanentes, } \\
\text { por classes de rendimento nominal mensal domiciliar } \\
\text { per capita }\end{array}$ & $\begin{array}{l}\text { Censo } \\
\text { Demográfico } \\
\text { IBGE } 2010\end{array}$ \\
\hline & $\begin{array}{l}\text { Mais de } 2 \text { a } 3 \text { salários } \\
\text { mínimos }\end{array}$ & $\begin{array}{l}\text { Tabela } 3261 \text { - Domicílios particulares permanentes, } \\
\text { por classes de rendimento nominal mensal domiciliar } \\
\text { per capita }\end{array}$ & $\begin{array}{l}\text { Censo } \\
\text { Demográfico } \\
\text { IBGE } 2010 \\
\end{array}$ \\
\hline & $\begin{array}{l}\text { Mais de } 3 \text { a } 5 \text { salários } \\
\text { mínimos }\end{array}$ & $\begin{array}{l}\text { Tabela } 3261 \text { - Domicílios particulares permanentes, } \\
\text { por classes de rendimento nominal mensal domiciliar } \\
\text { per capita }\end{array}$ & $\begin{array}{l}\text { Censo } \\
\text { Demográfico } \\
\text { IBGE } 2010 \\
\end{array}$ \\
\hline & $\begin{array}{l}\text { Mais de } 5 \text { salários } \\
\text { mínimos }\end{array}$ & $\begin{array}{l}\text { Tabela } 3261 \text { - Domicílios particulares permanentes, } \\
\text { por classes de rendimento nominal mensal domiciliar } \\
\text { per capita }\end{array}$ & $\begin{array}{l}\text { Censo } \\
\text { Demográfico } \\
\text { IBGE } 2010 \\
\end{array}$ \\
\hline & Sem rendimento & $\begin{array}{l}\text { Tabela } 3261 \text { - Domicílios particulares permanentes, } \\
\text { por classes de rendimento nominal mensal domiciliar } \\
\text { per capita }\end{array}$ & $\begin{array}{l}\text { Censo } \\
\text { Demográfico } \\
\text { IBGE } 2010 \\
\end{array}$ \\
\hline $\begin{array}{l}\text { Domicílios } \\
\text { (unidades) }\end{array}$ & $\begin{array}{l}\text { Domicílios ligados à } \\
\text { rede de água, com } \\
\text { banheiro privativo, } \\
\text { esgotamento sanitário, } \\
\text { energia elétrica e } \\
\text { coleta de lixo } \\
\end{array}$ & $\begin{array}{l}\text { Tabela } 3218 \text { - Domicílios particulares permanentes, } \\
\text { por forma de abastecimento de água, segundo a } \\
\text { existência de banheiro ou sanitário e esgotamento } \\
\text { sanitário, o destino do lixo e a existência de energia } \\
\text { elétrica }\end{array}$ & $\begin{array}{l}\text { Censo } \\
\text { Demográfico } \\
\text { IBGE } 2010\end{array}$ \\
\hline IDH-M & $\begin{array}{l}\text { Adaptação do IDH à } \\
\text { realidade brasileira, } \\
\text { realizada por meio } \\
\text { de uma parceria do } \\
\text { PNUD Brasil com o } \\
\text { Ipea e a Fundação } \\
\text { João Pinheiro }\end{array}$ & $\begin{array}{l}\text { IDH-M - obtido pela média geométrica dos três } \\
\text { subíndices das dimensões componentes do índice: } \\
\text { longevidade, educação e renda }\end{array}$ & $\begin{array}{l}\text { Atlas do } \\
\text { Desenvolvimento } \\
\text { Humano } 2012\end{array}$ \\
\hline \multirow[b]{3}{*}{$\begin{array}{l}\text { Finanças } \\
\text { municipais } \\
\mathrm{R} \$\end{array}$} & $\begin{array}{l}\text { Receitas } \\
\text { orçamentárias }\end{array}$ & Receitas orçamentárias & Finbra 2010 \\
\hline & $\begin{array}{l}\text { Despesas } \\
\text { orçamentárias }\end{array}$ & Despesas orçamentárias liquidadas & Finbra 2010 \\
\hline & PIB (R\$) & $\begin{array}{l}\text { Tabela } 5938 \text { - Produto Interno Bruto a preços } \\
\text { correntes, impostos, líquidos de subsídios, sobre } \\
\text { produtos a preços correntes e valor adicionado bruto } \\
\text { a preços correntes total e por atividade econômica, e } \\
\text { respectivas participações }\end{array}$ & $\begin{array}{l}\text { IBGE 2010, } \\
\text { em parceria } \\
\text { com órgãos } \\
\text { estaduais de } \\
\text { estatística, } \\
\text { secretarias } \\
\text { estaduais e } \\
\text { Suframa }\end{array}$ \\
\hline
\end{tabular}

Fonte: Elaboração dos autores.

Destaque-se que as variáveis de interesse para indicar o tamanho ótimo dos municípios são a população total e o termo quadrático dessa mesma variável, isto é, (população) ${ }^{2}$, que são utilizadas como variáveis explicativas na regressão em que a variável dependente é a despesa orçamentária dos municípios como proporção do PIB. Entretanto, para que a regressão seja validada é necessário utilizar variáveis de controle, ou seja, aquelas que 
também explicam o comportamento da variável dependente. Nesse sentido, utilizamos variáveis socioeconômicas e demográficas, além de dummies por faixa de população dos municípios até 50.000 habitantes. Tais variáveis de controle são muito importantes em função da forte heterogeneidade entre os municípios.

Entre as variáveis econômicas destacam-se os indicadores de finanças municipais, receitas e despesas orçamentárias, o PIB municipal e a renda per capita por faixa salarial. Quanto às variáveis sociais, são utilizados vários indicadores associados à educação e à infraestrutura domiciliar, tais como ligação à rede de água, banheiro privativo, esgotamento sanitário, energia elétrica e coleta de lixo. Além disso, emprega-se o Índice de Desenvolvimento Humano Municipal (IDH-M), que é um índice sintético com estrutura diferente das demais variáveis. Em outras palavras, o IDH-M é uma medida composta de indicadores de três dimensões do desenvolvimento humano: longevidade, educação e renda. 0 índice varia de 0 a 1: quanto mais próximo de 1, maior é o desenvolvimento humano. Dessa forma, utiliza-se uma variável de bem-estar como um indicador relevante em face da elevada heterogeneidade dos municípios. Quanto às variáveis demográficas, além da população dos municípios, introduz-se uma variável que leva em conta a estrutura etária dos diversos munícipios do Brasil.

A Tabela 1 apresenta as estatísticas descritivas das varáveis utilizadas nos modelos empíricos.

TABELA 1

Estatísticas descritivas

Municípios brasileiros da amostra (1) - 2010

\begin{tabular}{|c|c|c|c|c|c|}
\hline Variáveis & Média & Mediana & Máximo & Mínimo & $\begin{array}{l}\text { Desvio } \\
\text { padrão }\end{array}$ \\
\hline Despesa/PIB & 0,222121 & 0,191848 & 15,73891 & 0,000406 & 0,261712 \\
\hline População & $12.951,73$ & $9.704,00$ & $49.496,00$ & 805,0000 & $10.549,33$ \\
\hline $\begin{array}{l}\text { Renda até } 1 / 4 \text { salário } \\
\text { mínimo }\end{array}$ & 668,88 & 364,00 & $5.125,00$ & 2,00 & 781,44 \\
\hline Estrutura dos domicílios & $1.433,52$ & 585,00 & $15.128,00$ & 1,00 & $2.138,03$ \\
\hline $\begin{array}{l}\text { Ensino médio e superior } \\
\text { incompleto }\end{array}$ & $1.763,37$ & $1.130,00$ & $12.127,00$ & 93,00 & $1.778,19$ \\
\hline Receitas orçamentárias & $20.554 .503,00$ & $14.599 .461,00$ & $3,72 \mathrm{E}+08$ & $2.214 .650,00$ & $18.441 .705,00$ \\
\hline $\begin{array}{l}\text { Sem instrução, ensino } \\
\text { fundamental incompleto }\end{array}$ & $6.883,09$ & $5.200,00$ & $30.317,00$ & 381,00 & $5.398,59$ \\
\hline Ensino superior completo & 442,87 & 237,00 & $6.293,00$ & 11,00 & 574,20 \\
\hline $\mathrm{PIB}$ & $1,55 \mathrm{E}+08$ & $76.691 .500,00$ & $6,10 E+09$ & $5.727 .000,00$ & $2,84 \mathrm{E}+08$ \\
\hline Densidade demográfica & 38,34 & 22,30 & $2.206,17$ & 0,13 & 68,06 \\
\hline População rural & $4.526,69$ & $3.050,50$ & $31.640,00$ & 9,00 & $4.357,94$ \\
\hline Taxa de alfabetização & 84,55 & 87,30 & 99,10 & 58,40 & 8,88 \\
\hline Sem rendimento & 179,84 & 108,00 & $2.280,00$ & 1,00 & 205,50 \\
\hline Receitas/PIB & 0,22 & 0,20 & 2,05 & 0,003 & 0,12 \\
\hline IDH-M & 0.652 & 0.658 & 0.854 & 0.418 & 0.069 \\
\hline $\begin{array}{l}\text { Estrutura etária (razão de } \\
\text { dependência) }\end{array}$ & 0.520 & 0.503 & 1.180 & 0.137 & 0.088 \\
\hline
\end{tabular}

Fonte: Elaboração dos autores.

(1) Corresponde a 4.835 municípios. 
A Tabela 2 mostra a distribuição dos municípios brasileiros, segundo tamanho da população em 2010. Observa-se que 3.817 municípios, que representam $70 \%$ do total do Brasil, abrigam uma população de até 20 mil pessoas. Essa distribuição de municípios por tamanho populacional é, possivelmente, um dos problemas mais graves da economia brasileira, pois tais municípios possuem baixos níveis de receitas próprias e tornam-se dependentes de transferências constitucionais da União, assim como dos estados.

Também pode-se verificar, na Tabela 2, que $89 \%$ da população brasileira reside em cidades com até 50.000 habitantes, sendo uma amostra bastante expressiva para uma avaliação do tamanho ótimo para estas localidades, o que justifica a nossa escolha para o corte populacional. Destaque-se que, embora o Censo de 2010 registre 5.565 municípios em todo o país, utiliza-se o quantitativo de 5.430 que corresponde ao número de municípios que possuíam todos os dados de finanças municipais, conforme apresentado na Tabela 2. Entretanto, após um tratamento mais refinado dos dados, obteve-se uma amostra de 4.835 municípios, a qual mostra-se bastante representativa, sendo utilizada nos modelos empíricos aqui estudados.

TABELA 2

Distribuição dos municípios, segundo tamanho da população

Brasil - 2010

\begin{tabular}{lccc}
\hline População (em mil habitantes) & Quantidade de municípios & Quantidade acumulada & $\%$ \\
\hline Até 5 & 1.260 & 1.260 & 23,0 \\
Mais de 5 a 10 & 1.186 & 2.446 & 22,0 \\
Mais de 10 a 20 & 1.371 & 3.817 & 25,0 \\
Mais de 20 a 50 & 1.018 & 4.835 & 19,0 \\
Mais de 50 a 100 & 319 & 5.154 & 6,0 \\
Mais de 100 a 300 & 200 & 5.354 & 4,0 \\
Mais de 300 & 76 & 5.430 & 1,0 \\
\hline
\end{tabular}

Fonte: IBGE.

As análises empíricas são realizadas com base em regressões em que a variável dependente é representada pelas despesas públicas dos municípios como proporção do PIB e as principais variáveis de interesse são a população e o quadrado da população, pois pretende-se testar se há uma reação não linear entre a variável dependente e a população. As variáveis de controle são apresentadas no Quadro 1. A vantagem de utilizar a despesa pública/PIB como variável dependente é que, em termos de proporção, tal variável torna-se mais comparável entre os diversos municípios ao ser normalizada pelo PIB. Por outro lado, como estamos avaliando o tamanho da população ótima que contribui para minimizar a proporção da despesa em relação ao PIB, não utilizamos a despesa per capita como variável dependente, pois a população, sendo uma variável explicativa, afetaria o denominador da variável resposta ou dependente.

0 modelo empírico de dados de corte é explicitado da seguinte forma:

$Y_{i}=\delta_{o}+\delta_{1}^{\star}($ população_i $)+\delta_{2}{ }^{*}(\text { população_i })^{2}+\beta_{1}^{*} X_{1 i}+\beta_{2}{ }^{*} X_{2 i}+\ldots .+\beta_{n}{ }^{*} X_{n i}+e_{i}$ 
Onde $Y$ é a variável dependente, $\delta_{o}$ representa o termo da constante, $\delta_{1}$ é o coeficiente da população, $\delta_{2}$ é o coeficiente do quadrado da população, $i$ representa cada um dos municípios, tais que $i=1,2,3, \ldots, n$, e as variáveis de controle são representadas pelas variáveis de $X_{1}$ a $X_{n}$ com seus respectivos coeficientes de $\beta_{1}$ até $\beta_{n}$. Por fim, o termo do erro é dado por $e_{i}$.

Destaque-se ainda que, para se obter uma relação não linear entre a variável dependente e a variável de interesse (população), os coeficientes estimados de $\delta_{1}$ e $\delta_{2}$ precisam ser estatisticamente significantes e devem apresentar sinais opostos. Se $\delta_{1}$ apresenta sinal negativo e $\delta_{2}$ sinal positivo, isso significa que, à medida que aumenta o tamanho da população, há uma redução de $Y_{i}$ até um ponto de mínimo e, a partir desse ponto, aumentos sucessivos da população ocasionam um aumento de $Y_{i}$, gerando assim uma curva em forma de $\mathrm{U}$ ou uma curva côncava. Inversamente, se $\delta_{1}$ apresenta sinal positivo e $\delta_{2}$ sinal negativo, isso implica que, conforme aumenta o tamanho da população, há um aumento de $Y_{i}$ até um ponto de máximo e, a partir desse ponto, aumentos sucessivos da população levam a uma redução de $Y_{i}$, gerando assim uma curva em forma de $U$ invertida ou uma curva convexa.

As estimativas são realizadas pelo método de MQO, considerando-se erros padrão e covariância heterocedasticos consistentes com base nos testes de White-Hinkley (HC1). No que tange aos testes de robustez, utilizamos estimativas com base em modelos de MQO robustos. Na literatura há três tipos de modelos de MQO robustos: M-estimation (HUBER, 1973), S-estimation (ROUSSEEUW; YOHAI, 1984) e MM-estimation (YOHAI, 1987). Nesse contexto, emprega-se o método de MQO com base nos testes de White-Hinkley (HC1) com objetivo de corrigir problemas de heterocedastidade, ou de variância ou dispersão desigual, que é comum em modelos com dados de corte transversal ou cross-section. Utilizamos, por sua vez, como testes de robustez os modelos M-estimation, S-estimation e MM-estimation porque, justamente, tais métodos possuem erros padrão robustos de forma a não viesar os coeficientes estimados.

Quanto às variáveis de controle, buscamos indicadores socioeconômicos e demográficos que possam expressar o elevado grau de heterogeneidade dos municípios brasileiros. Nesse sentido, considerando-se ainda a dimensão continental do Brasil e a diversificação dos múltiplos aspectos regionais e culturais, utilizamos indicadores socioeconômicos (renda domiciliar per capita, educação, Índice de Desenvolvimento Humano dos Municípios) para capturar aspectos de bem-estar, estrutura dos domicílios e indicadores de finanças públicas, tais como as receitas orçamentárias que interagem com as faixas de população por municípios. No que se refere aos aspectos demográficos, empregamos variáveis como população urbana ou rural, dummies por faixa de população, densidade demográfica e estrutura etária. 


\section{Análise dos resultados empíricos}

A metodologia foi testada utilizando-se os dados dos municípios com de até 50.000 habitantes, que representam $89 \%$ da população brasileira. A Tabela 3 mostra que todos os coeficientes estimados são estatisticamente significantes ao nível de $5 \%$, exceto aqueles das variáveis densidade demográfica, renda até $1 / 4$ salário mínimo e as dummies de população de 10.001 a 20.000 e de 20.001 a 50.000. A variável população rural é marginalmente significante ao nível de $10 \%$. As variáveis de interesse - população e (população) ${ }^{2}$ - mostram coeficientes estimados nos valores de -1.11E-05 e 1.88E-10, respectivamente, indicando uma curva convexa. Os demais indicadores são variáveis de controle.

Os resultados obtidos na Tabela 3 mostram que existe uma relação não linear entre a variável dependente e a variável explicativa população na forma de $U$, que equivale a uma curva convexa. Nesse contexto, pode-se calcular a população que minimiza a razão entre despesa orçamentária e o PIB municipal. Dessa forma, para obter o tamanho ótimo da população, pode-se derivar a variável dependente em relação à população e igualar a zero, conforme apresentado a seguir:

Desp_pib $=-1.11 E-05^{*}$ pop $+1.88 E-10^{*}(p o p)^{2}$

Derivando temos que:

$d($ despesa orçamentária $/ P I B) / d($ população $)=-1.11 E-05+2^{*} 1.88 E-10^{*}$ pop $=0=>1.11 E-05=$ $3.76^{*}$ E-10pop $=>1.11=3.76^{*} E-05 p o p=>$ pop $p^{*}=(1.11 / 3.76)^{*} 100000 \Rightarrow$ pop* $=29.521,28$.

Os resultados empíricos com base na Tabela 3 mostram que o tamanho ótimo da população equivale a aproximadamente 29.521 pessoas. Vale ressaltar que, ao utilizarmos o valor predito, já estamos incorporando os efeitos das variáveis de controle na proporção despesa/PIB nas respectivas estimativas.

Destaque-se que os efeitos das variáveis de controle podem afetar a variável dependente, que é dada pela razão entre despesas orçamentárias e PIB e que, portanto, os efeitos dos indicadores de controle podem afetar o numerador e/ou o denominador e gerar um efeito líquido positivo ou negativo. Em outras palavras, deve-se importar mais com a significância estatística do que com a direção do sinal dos coeficientes estimados, sejam positivos ou negativos.

Os coeficientes estimados da população e do seu quadrado são estatisticamente significantes e apresentam uma relação não linear com a variável dependente, mostrando uma curva na forma de $U$, conforme mostra a Figura 1. 
FIGURA 1

Relação entre o valor predito da razão despesa/PIB (DESP_PIB_PREDITA) e população total Municípios brasileiros da amostra (1) - 2010

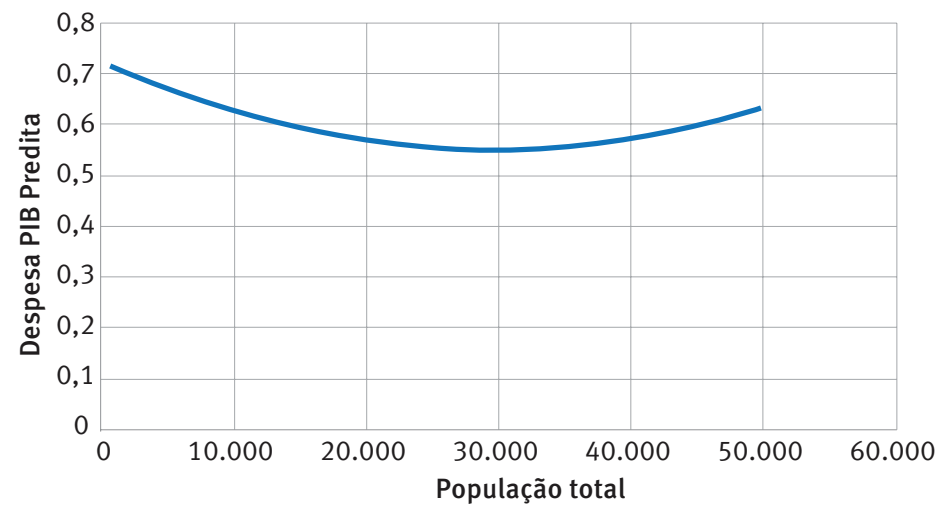

Fonte: Elaboração dos autores.

(1) Corresponde a 4.835 municípios.

Observam-se dummies por faixa de população utilizadas como variáveis de controle na Tabela 3, mas parte delas não é estatisticamente significante, como os coeficientes estimados das variáveis “dummy 10.001 a 20.000" e "dummy 20.001 a 50.000”, ao contrário das variáveis “dummy 2.001 a 5.000" e "dummy 5.001 a 10.000", que mostram coeficientes estimados estatisticamente diferentes de zero. Ressalte-se que, ao utilizarmos variáveis interativas entre as dummies por faixa de população e a razão receita orçamentaria/PIB, verifica-se que todos os coeficientes estimados são estatisticamente significantes. Essas variáveis interativas são o resultado do produto entre uma dummy por faixa de população vezes a razão da receita orçamentária/PIB. Por exemplo, a variável interativa apresentada na Tabela 3, (REC/PIB)*Dummy_ate_2.000, mostra o efeito das receitas como proporção do PIB sobre a variável dependente, levando em conta apenas os municípios com até 2.000 habitantes. Nesse caso, foi construído uma variável dummy em que todos os municípios de até 2.000 habitantes possuem valor igual a 1, enquanto aqueles com mais de 2.000 habitantes possuem valor 0 . Pode-se observar que tal variável interativa é estatisticamente significante ao nível de $1 \%$ e possui um valor estimado equivalente a 0.819354 . Como resultado, a referida variável interativa mostra que, no que se refere aos municípios de até 2.000 habitantes, quando aumenta a sua receita, a despesa como proporção do PIB também cresce.

Nota-se ainda que a variável demográfica "população rural” não tem efeito sobre a variável dependente ao nível de $5 \%$, embora seja marginalmente significante ao nível de $10 \%$. Quanto às variáveis socioeconômicas, aquela que se refere às pessoas com renda de até $1 / 4$ salário mínimo apresenta coeficiente estimado estatisticamente nulo. Entretanto, o coeficiente estimado relativo à variável de pessoas classificadas como "sem rendimentos" mostra-se estatisticamente significante ao nível de $5 \%$, assim como os coeficientes referentes às variáveis “ensino superior completo" e “estrutura de domicílios”. Quanto à análise dos resíduos, considerando-se estimativas cross-section, deve-se avaliar se os erros 
são hetrocedásticos. Dessa forma, deve-se utilizar o teste de Breusch-Pagan-Godfrey, no qual assume-se que os erros são homocedásticos. Com base no resultado apresentado na Tabela 3, a hipótese nula não é rejeitada, ou seja, os erros são homocedásticos, conforme estatística F ao nível de significância de $5 \%$. Este resultado mostra-se válido para todas as estimativas que se seguem.

TABELA 3

Variável dependente: despesa orçamentária/PIB (Método MQO) Municípios brasileiros da amostra (1) - 2010

\begin{tabular}{|c|c|c|c|c|}
\hline Variáveis & Coeficiente & Desvio padrão & Estatística t & Probabilidade \\
\hline Constante & 0.722271 & 0.064941 & 11.12198 & $<0.0001$ \\
\hline População & $-1.11 E-05$ & $5.02 \mathrm{E}-06$ & -2.213159 & 0.0269 \\
\hline (População)2 & $1.88 \mathrm{E}-10$ & $7.55 \mathrm{E}-11$ & 2.486672 & 0.0129 \\
\hline Dummy 2.001 a 5.000 hab. & 0.210147 & 0.011268 & 18.65031 & $<0.0001$ \\
\hline Dummy 5.001 a 10.000 hab. & 0.174429 & 0.019250 & 9.061191 & $<0.0001$ \\
\hline Dummy 10.001 a 20.000 hab. & 0.076859 & 0.056765 & 1.353995 & 0.1758 \\
\hline Dummy 20.001 a 50.000 hab. & 0.086130 & 0.067996 & 1.266693 & 0.2053 \\
\hline Densidade demográfica & $5.69 \mathrm{E}-05$ & 4.96E-05 & 1.146671 & 0.2516 \\
\hline População rural & $1.83 \mathrm{E}-06$ & 9.64E-07 & 1.896718 & 0.0579 \\
\hline Ensino superior completo & 9.97E-06 & 4.74E-06 & 2.101862 & 0.0356 \\
\hline Renda até 1 / 4 salário mínimo & $-1.76 \mathrm{E}-05$ & $1.38 \mathrm{E}-05$ & -1.276583 & 0.2018 \\
\hline Taxa de alfabetização & -0.007307 & 0.000608 & -12.01274 & $<0.0001$ \\
\hline$($ REC/PIB)*Dummy_ate_2.000 & 0.819354 & 0.032786 & 24.99123 & $<0.0001$ \\
\hline$(\mathrm{REC} / \mathrm{PIB})^{\star}$ Dummy10.001 a 20.000 & 0.698040 & 0.050330 & 13.86929 & $<0.0001$ \\
\hline (REC/PIB)*Dummy20.001 a 50.000 & 0.803198 & 0.084663 & 9.487030 & $<0.0001$ \\
\hline ESTRUTURA_DOMICILIOS & 2.67E-06 & 7.58E-07 & 3.520911 & 0.0004 \\
\hline SEM_RENDIMENTO & $-4.63 \mathrm{E}-05$ & $2.32 \mathrm{E}-05$ & -1.996807 & 0.0459 \\
\hline
\end{tabular}
SEM_RENDIMENTO Outras estatísticas e população ótima

\begin{tabular}{lll}
\hline População ótima $=36.513$ habitantes & R2 ajustado $=0.154$ & Teste Durbin-Watson $=2.018$ \\
& Estatística $F=55.601$ & Prob. Estatística F<0,0001 \\
\hline
\end{tabular}

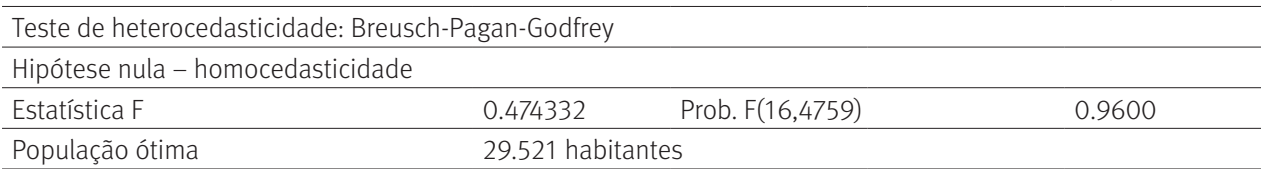

Fonte: Elaboração dos autores.

(1) Corresponde a 4.835 municípios.

Nota: Estimativa via MQO ajustado pelo método de Huber-White-Hinkley para corrigir possíveis problemas de heterocedasticidade no desvio padrão.

Nas regressões que se seguem retiram-se algumas variáveis apresentadas na Tabela 3, assim como adicionam-se novos indicadores com o objetivo de testar se será obtida uma relação não linear entre a variável dependente e a população total na forma de $U$, conforme Figura 1. Além disso, pode-se verificar se, com as alterações dos modelos, o valor da população ótima é muito sensível a essas mudanças. Por fim, procura-se mostrar a evolução dos diversos modelos empíricos até encontrar um modelo satisfatório e, ao mesmo tempo, mais parcimonioso. 
Na Tabela 4 reduz-se a quantidade de variáveis de controle e adiciona-se um novo indicador, que é IDH-M. Além disso, eliminam-se as variáveis interativas, a densidade demográfica e a renda até $1 / 4$ salário mínimo e substitui-se a população rural pela urbana. Mesmo com essas alterações, os resultados também mostram uma relação não linear entre a variável dependente e a população. Dessa forma, obtêm-se mais uma vez uma curva na forma de U e uma população ótima de 34.670 habitantes. Pode-se observar que todos os coeficientes estimados são estatisticamente significantes ao nível de $5 \%$, exceto os coeficientes estimados das variáveis relacionadas às faixas de população de até 2.000 habitantes e entre 2.001 e 5.000 habitantes. Vale ressaltar que o indicador de bem-estar dos municípios (IDH-M) é relevante, pois o coeficiente estimado negativo no valor de 0,61 é estatisticamente diferente de zero, mostrando que, quando os munícipios apresentam um maior bem-estar, há menores despesas como proporção do PIB, possivelmente porque os cidadãos são mais conscientes no sentido de fiscalizar a gestão municipal.

TABELA 4

Variável dependente: despesa orçamentária/PIB (Método MQO) Municípios brasileiros da amostra (1) - 2010

\begin{tabular}{lllll}
\hline \multicolumn{1}{c}{ Variáveis } & \multicolumn{1}{c}{ Coeficiente } & \multicolumn{1}{c}{ Desvio padrão } & Estatística t & \multicolumn{1}{c}{ Probabilidade } \\
\hline Constante & 1.267041 & 0.102670 & 12.34095 & $<0.00001$ \\
População & $-1.47 \mathrm{E}-05$ & $4.58 \mathrm{E}-06$ & -3.214192 & 0.0013 \\
(População) $^{2}$ & $2.12 \mathrm{E}-10$ & $7.40 \mathrm{E}-11$ & 2.864637 & 0.0042 \\
IDH-M & -0.614115 & 0.083150 & -7.385669 & $<0.00001$ \\
População urbana & $-3.86 \mathrm{E}-06$ & $1.01 \mathrm{E}-06$ & -3.803563 & 0.0001 \\
Taxa de alfabetização & -0.005743 & 0.000734 & -7.820903 & $<0.00001$ \\
Superior incompleto & $2.57 \mathrm{E}-05$ & $4.44 \mathrm{E}-06$ & 5.777814 & $<0.00001$ \\
Pop. até 2.000 & 0.038018 & 0.064891 & 0.585874 & 0.5580 \\
Pop. 2.001-5.000 & -0.050557 & 0.056983 & -0.887234 & 0.3750 \\
Pop. 5.001-10.000 & -0.084517 & 0.044058 & -1.918296 & 0.0551 \\
Pop. 10.001-20.000 & -0.027154 & 0.012251 & -2.216579 & 0.0267 \\
\hline
\end{tabular}

Outras estatísticas e população ótima

$\begin{array}{ll}\text { R2 ajustado }=0.123 & \text { Teste Durbin-Watson }=1.98 \\ \text { Estatística } F=68.695 & \text { Prob. estatística } F<0,0001\end{array}$

\begin{tabular}{|c|c|c|c|}
\hline Teste de heteroce & usch-Pagan & & \\
\hline Hipótese nula - h & & & \\
\hline Estatística F & 0.679847 & Prob. F(10,4822) & 0.7442 \\
\hline População ótima & 34.670 ha & & \\
\hline
\end{tabular}

Fonte: Elaboração dos autores.

(1) Corresponde a 4.835 municípios.

Nota: Estimativa via MQO ajustado pelo método de Huber-White-Hinkley para corrigir possíveis problemas de heterocedasticidade no desvio padrão.

Cabe destacar que as alterações com exclusões de variáveis e manutenção de outras deve-se a dois pontos básicos. 0 primeiro é que o modelo empírico apresentado na Tabela 3 é o menos parcimonioso, pois apresenta muitas variáveis explicativas, e como objetivamos um modelo mais parcimonioso, mas também representativo, eliminamos algumas variáveis em excesso apresentadas na Tabela 3. O segundo ponto é que optamos por 
sempre manter algumas variáveis socioeconômicas nos modelos, como indicadores de educação, população urbana ou rural e variáveis de bem-estar, como estrutura domiciliar das famílias ou o IDH-M.

Por fim, a Tabela 5 mostra um modelo mais parcimonioso com todos os coeficientes estimados significantes ao nível de $5 \%$. Confirma-se, mais uma vez, uma curva na forma de U que revela uma população ótima de 28.877 habitantes. Todos os coeficientes estimados são estatisticamente significantes ao nível de $5 \%$. Esse modelo utiliza, além das variáveis de população, apenas dois indicadores de educação e a variável de infraestrutura domiciliar.

TABELA 5

Variável dependente: despesa orçamentária/PIB(Método MQO) Municípios brasileiros da amostra (1) - 2010

\begin{tabular}{lcccc}
\hline \multicolumn{1}{c}{ Variáveis } & Coeficiente & Desvio padrão & Estatística t & P-valor \\
\hline Constante & 1.086629 & 0.045230 & 24.02448 & $<0.00001$ \\
População & $-1.08 \mathrm{E}-05$ & $7.95 \mathrm{E}-07$ & -13.55544 & $<0.00001$ \\
População) $^{2}$ & $1.87 \mathrm{E}-10$ & $2.26 \mathrm{E}-11$ & 8.272668 & $<0.00001$ \\
Taxa de alfabetização & -0.009230 & 0.000505 & -18.29096 & $<0.00001$ \\
População urbana & $-5.73 \mathrm{E}-06$ & $1.17 \mathrm{E}-06$ & -4.883474 & $<0.00001$ \\
Estrutura dos domicílios & $2.24 \mathrm{E}-06$ & $9.93 \mathrm{E}-07$ & 2.255380 & 0.0242 \\
Ensino médio incompleto & $2.88 \mathrm{E}-05$ & $6.50 \mathrm{E}-06$ & 4.430418 & $<0.00001$ \\
\hline \multicolumn{5}{c}{ Outras estatísticas e população ótima } \\
\hline \multicolumn{4}{c}{ Teste Durbin-Watson $=1.98$} \\
\hline
\end{tabular}

Teste de heterocedasticidade: Breusch-Pagan-Godfrey

Hipótese nula - homocedasticidade

\begin{tabular}{|c|c|c|c|}
\hline Estatística F & 0.303599 & Prob. F(6,4795) & 0.9353 \\
\hline População ótima & 28.877 habitantes & & \\
\hline
\end{tabular}

Fonte: Elaboração dos autores.

(1) Corresponde a 4.835 municípios.

Nota: Estimativa via MQO ajustado pelo método de Huber-White-Hinkley para corrigir possíveis problemas de heterocedasticidade.

Os dados apresentados nas Tabelas 3 a 5 confirmam uma relação não linear entre a variável dependente e a população, com base em diferentes modelos de MQO, com diferentes variáveis de controle. Por fim, adiciona-se mais uma variável sugerida por um dos parecerista para ser testada, que é a variável de estrutura etária. Os resultados empíricos apresentados na Tabela 6 são similares aos da Tabela 5, exceto pelo efeito estatisticamente significante do coeficiente estimado da variável estrutura etária, definida como a razão entre a população “não ativa” (até 14 anos e após 65 anos) e a população economicamente ativa, entre 15 anos e 64 anos. 0 coeficiente estimado da variável estrutura etária, mais conhecida na literatura demográfica e econômica como razão de dependência, mostra um impacto diretamente proporcional sobre a variável dependente no valor de 0.200578 .

Vale ressaltar que municípios com alta razão de dependência - (pop. 14 anos ou menos + pop. 65 anos ou mais) / (pop. de 15 a 64 anos) - podem gerar gastos maiores, seja com educação, caso a população seja muito jovem, ou com saúde, para aqueles municípios com estrutura 
etária mais envelhecida, sobretudo se o município é um polo regional para atenção à saúde. Além disso, no caso dos municípios com estrutura etária envelhecida, principalmente aqueles de população pequena, a renda oriunda das aposentadorias dos residentes pode ter considerável importância para a composição do PIB local. Nesse contexto, justifica-se a inclusão da variável “razão de dependência” na Tabela 6. Ante o exposto, estas questões podem ser objeto de novos estudos, que poderão contribuir para novas pesquisa sobre este tema.

TABELA 6

Variável dependente: despesa orçamentária/PIB (Método MQO) Municípios brasileiros da amostra (1) - 2010

\begin{tabular}{lcccc}
\hline \multicolumn{1}{c}{ Variáveis } & Coeficiente & Desvio padrão & Estatística t & P-valor \\
\hline Constante & 0.899199 & 0.076691 & 11.72489 & $<0.0001$ \\
População & $-1.21 \mathrm{E}-05$ & $8.22 \mathrm{E}-07$ & -14.67081 & $<0.0001$ \\
(População) $^{2}$ & $1.89 \mathrm{E}-10$ & $2.27 \mathrm{E}-11$ & 8.340303 & $<0.0001$ \\
Taxa de alfabetização & -0.008212 & 0.000665 & -12.34688 & $<0.0001$ \\
População urbana & $-5.43 \mathrm{E}-06$ & $1.19 \mathrm{E}-06$ & -4.557459 & $<0.0001$ \\
Estrutura dos domicílios & $3.81 \mathrm{E}-06$ & $9.80 \mathrm{E}-07$ & 3.884382 & 0.0001 \\
Ensino médio incompleto & $3.38 \mathrm{E}-05$ & $5.92 \mathrm{E}-06$ & 5.717738 & $<0.0001$ \\
Estrutura etária (razão de dependência) & 0.200578 & 0.041237 & 4.864048 & $<0.0001$ \\
\hline & \multicolumn{2}{c}{ Outras estatísticas e população ótima } & Teste Durbin-Watson $=1.98$ \\
\hline
\end{tabular}

Teste de heterocedasticidade: Breusch-Pagan-Godfrey

Hipótese nula - homocedasticidade

\begin{tabular}{|c|c|c|c|}
\hline Estatística F & 0.319448 & Prob. F(7,4794) & 0.9456 \\
\hline População ótima & 32.011 ha & & \\
\hline
\end{tabular}

Fonte: Elaboração dos autores.

(1) Corresponde a 4.835 municípios.

Nota: Estimativa via MQO ajustado pelo método de Huber-White-Hinkley para corrigir possíveis problemas de heterocedasticidade.

Nesse contexto, vale também destacar a relevância do Bolsa Família, Benefício de Prestação Continuada da Assistência Social (BPC) e outros programas de transferência de renda, além da importância relativa dos valores da aposentadoria rural, uma vez que tais programas sociais e assistenciais estão associados aos municípios mais pobres.

A Tabela 7 mostra uma proxy do custo fixo médio dos municípios da amostra. 0 custo fixo dos municípios equivale a um valor aproximado da média da variável dependente, que é de 0,222121 , conforme a Tabela 1 . Isso significa que, se o município parasse com todas as prestações de bens e serviços, ainda assim teria um custo fixo de 0,222126. Pode-se observar que o custo fixo está abaixo do ponto de mínima despesa dos municípios conforme estimativas relativas apresentadas nos nas Tabelas 3 a 6. Portanto, a diferença entre o valor das despesas mínimas como proporção do PIB e o custo fixo equivale a uma proxy para o custo variável. Dessa forma, o custo fixo equivale a $22,21 \%$ da despesa pública como proporção do PIB, o que significa que, em média, nenhum município pode ter uma despesa como proporção do PIB menor do que 0,222126. Assim, o custo fixo poderia ser 
visualizado com uma reta horizontal no eixo da abscissa, no qual estaria situado abaixo dos pontos que minimizam as despesas como proporção do PIB.

TABELA 7

Variável dependente: despesa orçamentária/PIB (Método MQO)

Municípios brasileiros da amostra (1) - 2010

\begin{tabular}{ccccc}
\hline Variáveis & Coeficiente & Desvio padrão & Estatística t & Probabilidade \\
\hline Constant & 0.222126 & 0.003763 & 59.02270 & $<0.0001$ \\
\hline \multicolumn{4}{c}{ Estatísticas } \\
\hline & R2 ajustado $=<0.0001$ & \multicolumn{3}{c}{ Teste Durbin-Watson $=1.953$} \\
\hline
\end{tabular}

Fonte: Elaboração dos autores.

(1) Corresponde a 4.835 municípios.

Por fim, destaca-se entre os resultados apresentados que, além de observarmos uma relação não linear na forma de U em todos os modelos estimados, há diversos níveis ótimos de população que variam entre 28.877 e 34.670 habitantes. 0 valor médio das estimativas do nível ótimo populacional é de aproximadamente 31.270 habitantes. Nesse contexto, faremos a seguir alguns testes de robustez para definirmos o nível ótimo populacional.

Testes de robustez

TABELA 8

Variável dependente: despesa orçamentária/PIB

Municípios brasileiros da amostra (1) - 2010

\begin{tabular}{|c|c|c|c|c|c|c|}
\hline \multirow[t]{2}{*}{ Variáveis } & \multicolumn{2}{|c|}{ Método: M-estimação } & \multicolumn{2}{|c|}{ Método: S-estimação } & \multicolumn{2}{|c|}{ Método: MM-estimação } \\
\hline & $\begin{array}{c}\text { Coeficiente } \\
\text { (desvio-padrão) }\end{array}$ & P-valor & $\begin{array}{c}\text { Coeficiente } \\
\text { (desvio-padrão) }\end{array}$ & P-valor & $\begin{array}{c}\text { Coeficiente } \\
\text { (desvio-padrão) }\end{array}$ & P-valor \\
\hline Constante & $\begin{array}{c}1.027740 \\
(0.014007)\end{array}$ & $<0.001$ & $\begin{array}{c}1.03111 \\
(0.018066)\end{array}$ & $<0.001$ & $\begin{array}{c}1.027800 \\
(0.014006)\end{array}$ & $<0.001$ \\
\hline População & $\begin{array}{l}-9.82 \mathrm{E}-06 \\
(5.20 \mathrm{E}-07)\end{array}$ & $<0.001$ & $\begin{array}{l}-8.13 \mathrm{E}-06 \\
(6.70 \mathrm{E}-07)\end{array}$ & $<0.001$ & $\begin{array}{c}-9.82 \mathrm{E}-06(5.20 \mathrm{E}- \\
07)\end{array}$ & $<0.001$ \\
\hline (População)² & $\begin{array}{l}1.55 \mathrm{E}-10 \\
(8.22 \mathrm{E}-12)\end{array}$ & $<0.001$ & $\begin{array}{l}1.18 \mathrm{E}-10 \\
(1.06 \mathrm{E}-11)\end{array}$ & $<0.001$ & $\begin{array}{c}1.55 \mathrm{E}-10 \\
(8.22 \mathrm{E}-12)\end{array}$ & $<0.001$ \\
\hline $\begin{array}{l}\text { Taxa de } \\
\text { alfabetização }\end{array}$ & $\begin{array}{c}-0.008754 \\
(0.000159)\end{array}$ & $<0.001$ & $\begin{array}{c}-0.009094 \\
(0.000205)\end{array}$ & $<0.001$ & $\begin{array}{l}-0.008755 \\
(0.000159)\end{array}$ & $<0.001$ \\
\hline Pop. urbana & $\begin{array}{l}-3.67 \mathrm{E}-06 \\
(4.76 \mathrm{E}-07)\end{array}$ & $<0.001$ & $\begin{array}{l}-2.71 E-06 \\
(6.14 E-07)\end{array}$ & $<0.001$ & $\begin{array}{c}-3.67 \mathrm{E}-06(4.76 \mathrm{E}- \\
07)\end{array}$ & $<0.001$ \\
\hline $\begin{array}{l}\text { Estrutura do } \\
\text { domicílio }\end{array}$ & $\begin{array}{l}2.60 \mathrm{E}-0 \\
(9.49 \mathrm{E}-07)\end{array}$ & 0.0061 & $\begin{array}{c}4.25 \mathrm{E}-0 \\
(1.22 \mathrm{E}-06)\end{array}$ & 0.0005 & $\begin{array}{c}2.61 \mathrm{E}-06 \\
(9.49 \mathrm{E}-07)\end{array}$ & 0.0060 \\
\hline \multirow[t]{2}{*}{$\begin{array}{l}\text { Ensino médio } \\
\text { incompleto }\end{array}$} & $\begin{array}{l}2.07 \mathrm{E}-05 \\
(3.45 \mathrm{E}-06 \mathrm{p}\end{array}$ & $<0.001$ & $\begin{array}{l}1.61 \mathrm{E}-05 \\
(4.45 \mathrm{E}-06)\end{array}$ & 0.0003 & $\begin{array}{l}2.07 \mathrm{E}-05 \\
(3.45 \mathrm{E}-06)\end{array}$ & $<0.001$ \\
\hline & \multicolumn{6}{|c|}{ Estatísticas robustas e população ótima } \\
\hline R2 ajustado & \multicolumn{2}{|l|}{0.441454} & \multicolumn{2}{|c|}{0.383773} & \multicolumn{2}{|l|}{0.441143} \\
\hline População ótima & \multicolumn{2}{|l|}{31.667} & \multicolumn{2}{|l|}{34.449} & \multicolumn{2}{|l|}{31.667} \\
\hline
\end{tabular}

Fonte: Elaboração dos autores.

(1) Corresponde a 4.835 municípios.

Os resultados das estimativas com base no método de MQO com erro robusto, conforme a Tabela 7, mostram que todos os coeficientes estimados são estatisticamente significantes ao nível de 1\%. Entretanto, os respectivos R2 ajustados referentes aos métodos M-estimação e MM-estimação possuem o R2 superior ao método S-estimação. Nesse 
contexto, com base nesses testes, a população ótima equivale a 31.667 habitantes. Por fim, enfatizamos que as estimativas da Tabela 8 apresentam erros ou resíduos robustos para os três métodos apresentados.

Ante o exposto, observa-se que a população ótima de 31.667 habitantes obtida na Tabela 8 é muito próxima do valor médio das estimativas do nível ótimo populacional apresentado na subseção anterior, de aproximadamente de 31.270 habitantes, calculado com base na média dos valores mostrados nas Tabelas 3 a 6 .

\section{Conclusões}

Os resultados empíricos obtidos mostram que, com base num recorte populacional de até 50.000 habitantes, o nível ótimo de população equivale a aproximadamente 31.667 habitantes por cidade. Considerando-se as despesas orçamentárias como proporção do PIB em relação à população, pode-se obter o quantitativo populacional que indica o ponto de mínimo da parábola de uma curva na forma de U, o qual mostra o melhor nível populacional na média que minimiza as despesas públicas como proporção do PIB. Nesse contexto, sucessivos incrementos do quantum populacional até o ponto de mínimo da curva em forma de $U$ geram ganhos de escala.

Segundo Holzer et al. (2009), a curva em formato de U retrata a relação entre o tamanho ótimo do município e sua eficiência, a qual podemos entender como uma analogia quanto à relação aqui desenvolvida entre a razão das despesas orçamentárias e o PIB em relação à população. Nesse caso, à medida que a população aumenta até atingir o ponto de mínimo da curva na forma de $U$, ela contribui para reduzir os custos per capita das prestações de serviços públicos, indicando ganhos de escala. Segundo Blom-Hansen et al. (2014), a curva em forma de U sugere que há um tamanho ótimo para o governo local e que os municípios com mais habitantes apresentam menor custo administrativo per capita, confirmando, assim, a economia de escala.

No Brasil, em decorrência da fragmentação de territórios ocorrida após a Constituição de $1988,70 \%$ dos municípios possuem população inferior a 20 mil habitantes e $89 \%$ têm menos de 50.000 habitantes. Essa distribuição de municípios por tamanho populacional é, possivelmente, um dos problemas mais graves da economia brasileira, pois tais municípios possuem baixas receitas próprias e ficam dependentes de transferências constitucionais da União e dos estados. A pesquisa desenvolvida por Lima e Leite (2020) conclui que o fracionamento dos municípios brasileiros provocou acréscimo nas contas públicas. $\mathrm{Na}$ mesma linha, Luduvice e De Biase (2020) estimam que o aumento nos gastos públicos ocasionado pelas emancipações municipais gira em torno de $\mathrm{R} \$ 25$ bilhões.

Como limitação deste estudo, avaliamos que as análises empíricas não são suficientes para que se encaminhe como conclusão a proposta de agrupamento de municípios, pois tal argumento deixa de considerar outros fatores que atuam no processo de fragmentação municipal e que não estão necessariamente vinculados a razões econômicas. Dessa 
forma, para que uma proposta de junção de munícipios seja implementada, fica como sugestão para próximas pesquisas sobre o tema a realização de um estudo situado em um campo mais experimental, sendo, por isso, um exercício de avaliação que necessitaria de outros elementos para uma conclusão mais definitiva. É importante também ressaltar que o critério de tamanho ótimo dos municípios não garante uma gestão eficiente por parte da administração municipal, que envolve fatores para além daqueles situados na esfera econômico-financeira.

\section{Referências}

ANDREWS, R. Vertical consolidation and financial sustainability: evidence from English local government. Environment and Planning C: Government and Policy, v. 33, n. 6, p. 1518-1545, 2015.

BARTOLINI, D. Municipal fragmentation and economic performance of OECD TL2 Regions. Paris: OCDE, 2015. (OECD Regional Development Working Papers).

BLESSE, S.; BASKARAN, T. Do municipal mergers result in scale economies? Evidence from a German Federal State. Centre for European Governance and Economic Development Research, 2013. (Discussion Papers, n. 176).

BLOM-HANSEN, J.; HOULBERG, K.; SERRITZLEW, S. Size, democracy, and the economic costs of running the political system. American Journal of Political Science, v. 58, n. 4, p. 790-803, 2014.

BREMAEKER, F. E. J. A importância do FPM para as finanças municipais e seu papel na equalização das receitas. Salvador: Associação Transparência Municipal, 2010. (Estudo Técnico, n. 105).

BYRNES, J.; DOLLERY, B. Do economies of scale exist in australian local government? A review of the research evidence. Urban Policy and Research, v. 20, n. 4, p. 391-414, 2002.

DAHIS, R; SZERMAN, C. Decentralizing development. Job Market Paper, 2020.

DREW, J.; KORTT, M. A.; DOLLERY, B. Economies of scale and local government expenditure: evidence from Australia. Administration and Society, v. 46, n. 6, p. 632-653, 2014.

DOLLERY, B.; EUAN, F. A conceptual note on scale economies, size economies and scope economies in Australian local government. Urban Policy and Research, v. 24, n. 2, p. 271-282, 2006.

GASPARINI, C. E.; MIRANDA, R. B. Transferências, equidade e eficiência municipal no Brasil. Planejamento e Políticas Públicas, n. 36, jan./jun. 2011.

GENDZWILL, A.; KURNIEWICZ, A.; SWIANIEWICZ, P. The impact of municipal territorial reforms on the economic performance of local governments. A systematic review of quasi-experimental studies. Space and Polity, v 25, p. 1-20, 2020.

GOMES, G. M.; MAC DOWELL, M. C. Descentralização política, federalismo fiscal e criação de municípios: o que é mau para o econômico nem sempre é bom para o social. Brasília: Ipea, 2000. (Texto para Discussão, n. 706).

GUEDES, K. P.; GASPARINI, C. E. Descentralização fiscal e tamanho do governo no Brasil. Economia Aplicada, São Paulo, v. 11, n. 2, p. 303-323, abr.-jun. 2007.

GRUBER, J. Finanças públicas e política pública. Macmillan Learning, 2016.

HOLCOMBE, R. G.; WILLIAMS, D. W. Are there economies of scale in municipal government expenditures? Public Finance and Management, v. 9, n. 3, p. 416-438, 2009. 
HOLZER, M.; FRY, J.; CHARBONNEAU, E.; VAN RYZIN, G.; WANG, T.; BURNASH, E. Literature review and analysis related to optimal municipal size and efficiency. Newark: School of Public Affairs and Administration (Rutgers), 2009.

HOULBERG, K. Municipal size, economy, and democracy. In: SWIANIEWICZ, P. (ed.). Territorial consolidation reforms in Europe. Budapest: OSI / LGI, 2010. p. 309-331.

HUBER, P. J. Robust regression: asymptotics, conjectures and Monte Carlo. The Annals of Statistics, v. 1, n. 5, p. 799-821, 1973.

KORTT, M. A.; DOLLERY, B.; DREW, J. Municipal mergers in New Zealand: an empirical analysis of the proposed amalgamation of Hawke's Bay councils. Local Government Studies, v. 42, n. 2, p. 228-247, 2015.

LIMA, R. C. A.; LEITE, V. M. B. O efeito da emancipação de munícipios sobre as finanças públicas locais: evidências para o Brasil. Revista Cadernos de Finanças Públicas, Brasília, v. 2, n. 1, p. 1-34, edição especial 2021.

LINDAHL E. Just taxation - a positive solution. In: MUSGRAVE, R. A.; PEACOCK, A. T. (ed.). Classics in the theory of public finance. London: Palgrave Macmillan, 1958. (International Economic Association Series).

LUDUVICE, F.; DE BIASE, P. Efeitos fiscais das subdivisões municipais no Brasil após 1988. Revista Cadernos de Finanças Públicas, Brasília, v. 20, n. 2, p. 1-25, set. 2020.

MATEJOVA, L.; NEMEC, J.; KRAPEK, M.; KLIMOVSKY, D. Economies of scale on the municipal level: fact or fiction in the Czech Republic? Journal of Public Administration and Policy, v. 10, n. 1, p. 39-59, 2017.

MENDES, M. Federalismo fiscal. In: AVARTE, P.; BIRDEMAN, C. Economia do setor público no Brasil. [S.I.]: Elsevier, 2004.

MOISIO, A.; UUSITALO, R. The impact of municipal mergers on local public expenditure in Finland. Public Finance and Management, v. 13, n. 3, p. 148-66, 2013.

MUSGRAVE, R. A. The voluntary exchange theory of public economy. Oxford: Oxford University Press, 1939.

OATES, W. E. Fiscal federalism. United Kingdom: Edward Elgar Publishing, 1972.

ROUSSEEUW, P. J.; YOHAI, V. J. Robust regression by means of s-estimators. In: FRANKE, J.; HÄRDLE, W.; MARTIN, D. (ed.). Robust and nonlinear time series analysis. Belin; New York: Springer-Verlag, 1984.

SAMUELSON, P. The pure theory of public expendure. The MIT Press, 1954.

SANDMO, A. Public goods. In: EATWELL, J.; MILGATE, M.; NEWMAN, P. (ed.). Allocation, information and market. [S.I.]: Palgrave Macmillan, 1989. p. 254-266.

SANTOS, L. B. dos; MIRANDA, R. B.; MOREIRA, T. B. S. A pobreza no Brasil e as estratégias de superação. Revista de Economia e Agronegócio, v. 10, p. 359-396, 2012.

SOUKOPOVÁ, J.; NEMEC, J.; MATEJOVA, L.; STRUCK, M. Municipality size and local public services: do economies of scale exist? Journal of Public Administration and Policy, v. 7, n. 2, p. 151-171, 2014.

SOUZA, M. C. S.; RAMOS, F. Eficiência técnica e retornos de escala na produção de serviços públicos municipais: o caso do Nordeste e do Sudeste brasileiros. Revista Brasileira de Economia, v. 4, p. 433-461, 1999.

SWIANIEWICZ, P.; LUKOMSKA, J. Is small beautiful? The quasi-experimental analysis of the impact of territorial fragmentation on costs in polish local governments. Urban Affairs Review, 2017. 
TIEBOUT, C. A pure theory of local expenditures. Journal of Political Economy, v. 64, n. 5 , p. 416-424, 1956.

YOHAI, V. J. High breakdown-point and high efficiency robust estimates for regression. The Annals of Statistics, v. 15, n. 2, p. 642-656, 1987.

\title{
Sobre os autores
}

Tito Belchior Silva Moreira é doutor em Economia pela Universidade de Brasília (UnB). Professor e pesquisador do Departamento de Economia da Universidade Católica de Brasília (UCB).

Anna Rita Scott Kilson é mestre em Economia em Políticas Públicas pela Universidade Católica de Brasília (UCB). Economiária, Caixa Econômica Federal.

Celso Vila Nova de Souza é doutor em Economia pela Universidade de Brasília (UnB). Professor e coordenador do Programa de Pós-graduação em Gestão Pública da UnB.

\section{Endereço para correspondência}

\author{
Tito Belchior Silva Moreira \\ SQN 308, Bloco A, apto. 101, Asa Norte \\ 70747-010 - Brasília-DF, Brasil \\ Anna Rita Scott Kilson \\ SQSW 302, Bloco A, apto. 506, Sudoeste \\ 70.673-201 - Brasília-DF, Brasil \\ Celso Vila Nova de Souza \\ QN29, conjunto 07, casa 02, Riacho Fundo II \\ 71880-681 - Brasília-DF, Brasil
}

\section{Abstract}

\section{An Empirical Assessment of the Optimal Size of Municipalities}

This research aims to carry out an empirical investigation on the optimal size of the municipalities, that is, the number of inhabitants that offers the lowest level of expenditure in relation to the municipal GDP, obtaining an economic scale to provide the best level of public resources. This study analyzes a sample of data from 4.835 municipalities with a population of less than 50,000 inhabitants, which represent $89 \%$ of the total Brazilian municipalities. The database gathers information on municipal revenues and expenses extracted from Finance of Brazil - Accounting Data of Municipalities - FINBRA 2010, socioeconomic data from the 2010 IBGE Demographic Census and the municipalities GDP from the 2010 IBGE. The outcomes showed that the optimal population size for a Brazilian municipality is equivalent to 31.667 inhabitants per city, based on Ordinary Least Squares (OLS) with robust standards errors. This population size provides gains of scale in public administration and improves local autonomy in relation to the central government in order to offer quality public goods.

Keywords: Fiscal federalism. Optimal municipal size. Public expenditure. 


\section{Resumen}

Una evaluación empírica del tamaño ideal de los municipios

Esta investigación tiene como objetivo realizar una investigación empírica sobre el tamaño óptimo de los municipios, es decir, sobre el número de habitantes que proporciona el menor nivel de gasto en relación al producto bruto interno (PIB) municipal, de manera de obtener la escala económica para la optimización de la aplicación de recursos públicos. Para ello analiza una muestra de datos de 4835 municipios con una población de menos de cincuenta mil habitantes, lo que representa el $89 \%$ de todos los municipios brasileños. La base de datos recopila información sobre ingresos y gastos municipales, extraídos de Finanzas de Brasil-Datos contables municipales-FINBRA 2010, datos socioeconómicos del censo demográfico del IBGE de 2010 y datos del PIB de los municipios en 2010. Los resultados empíricos informaron que el tamaño ideal de la población de un municipio brasileño es equivalente a aproximadamente 31.667 habitantes por ciudad, según métodos econométricos, como enteros cuadrados ordinarios con desviación estándar robusta. Este tamaño de población ofrece ganancias de escala en la administración pública y otorga mayor autonomía local en relación con el gobierno central para ofrecer bienes públicos de calidad.

Palabras clave: Federalismo fiscal. Tamaño óptimo de los municipios. Gasto público.

Recebido para publicação em 22/05/2021

Aceito para publicação em 08/09/2021 